\title{
Reverse-direction video-assisted thoracoscopic surgery left upper lobectomy via interlobar fissure: a case report
}

\author{
Shixin Zhang, Xi Liu, Jie Liu, Shuai Liu, Wei Wu, Haidong Wang \\ Department of Thoracic Surgery, Southwest Hospital, Army Medical University (Third Military Medical University), Chongqing, China \\ Correspondence to: Wei Wu. Department of Thoracic Surgery, Army Medical University (Third Military Medical University), Gaotanyan Street, \\ Shapingba District, Chongqing 400038, China. Email: wuweiyahoo@sohu.com.
}

\begin{abstract}
With the development of video-assisted thoracoscopic surgery (VATS), lobectomy has evolved from the traditional four-port and three-port techniques to two-port (also known as single utility port) and single-port. Optimizing surgical procedures to ensure safety remains one of the main problems faced by thoracic surgeons. Due to the limitations of operation space and angles, it is difficult to dissociate the pulmonary vein and the upper trunk of pulmonary artery using a single utility port and single-port VATS left upper lobectomy, and there is considerable risk of vessels rupturing and bleeding. After reviewing a large number of previous practices, we optimized the surgical sequence of left upper lobectomy under VATS. In this paper, we report a patient with a clinical diagnosis of primary lung cancer in stage IA3 (T1cN0M0) who underwent a single utility port VATS left upper lobectomy and lymph node dissection. In surgery, we first cut open the anterior and posterior mediastinal pleura of the left upper lobe (LUL), and then transected $\mathrm{A}^{4+5}$ and $\mathrm{A}^{1+2} \mathrm{c}$ branches, the left upper bronchus, the upper trunk of the left pulmonary artery, and the left upper pulmonary (LUP) vein from bottom to top through the interlobar fissure in turn. We believe that this method helps expose the upper trunk of the left pulmonary artery and the LUP vein, simplifies the steps in the operation, and improves overall safety.
\end{abstract}

Keywords: Video-assisted thoracoscopic surgery (VATS); left upper lobectomy; single utility port; interlobar fissure; case report

Received: 02 July 2021; Accepted: 20 October 2021; Published: 30 January 2022.

doi: $10.21037 /$ shc-21-15

View this article at: https://dx.doi.org/10.21037/shc-21-15

\section{Introduction}

Anatomical lobectomy plus lymph node dissection is one of the standard surgical methods used to treat non-small cell lung cancer (NSCLC). Minimally invasive surgery represented by video-assisted thoracoscopic surgery (VATS) has become the main thoracic surgery for NSCLC. With the development of surgical technology and the improvement in endoscopic instruments, VATS chest wall incisions have shifted from the traditional four ports and three ports to twoports (also called single utility port) and single port. Because all operations involving a single utility port and single-port VATS are completed with limited access, which restricts the instruments and operating angle, these operations have considerable difficulty. On the premise of reducing the number of chest wall incisions, many institutions have proposed different methods on how to optimize the surgical procedures and ensure the safety and thoroughness of the operation (1-3). Usually, the surgical sequence of VATS upper left lobectomy is to first transect the left upper pulmonary (LUP) vein or the upper trunk of left pulmonary artery, then transect the LUP bronchus, and finally separate the interlobar fissure. After gaining considerable experience in the early stage, we have optimized the surgical procedures of left upper lobectomy. We first transected the $\mathrm{A}^{4+5}$ and $\mathrm{A}^{1+2} \mathrm{c}$ branches, the LUP bronchus, the upper trunk of the left pulmonary artery, and the LUP vein from bottom to top through the interlobar fissure, which is the reverse of the traditional sequence. It is called reverse-direction. This video 


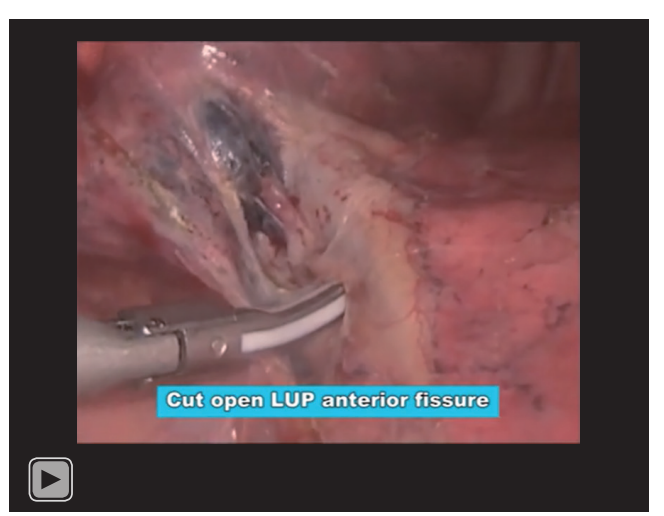

Video 1 Reverse-direction video-assisted thoracoscopic surgery left upper lobectomy via interlobar fissure.

aims to present the surgical procedures and main points of reverse-direction VATS left upper lobectomy via interlobar fissure. We present the following article in accordance with the CARE reporting checklist (available at https://shc. amegroups.com/article/view/10.21037/shc-21-15/rc).

\section{Case presentation}

A 50-year-old female patient was admitted to the hospital because a LUP nodule had been present for more than 3 months, found via physical examination. Preoperative chest CT imaging showed that a subsolid nodule opacity in the LUL with high-density opacity in the center and ground-glass opacity on the edge. It was about $23^{*} 15 \mathrm{~mm}$ in size, with unclear borders, and bronchial dislocation was visible inside. Lung function was assessed with a forced expiratory volume in 1 second (FEV1) of $2.0 \mathrm{~L}$ (actual/ predicted $=91.0 \%$ ), and maximal voluntary ventilation (MVV) of $83.1 \mathrm{~L} / \mathrm{min}$ (actual/predicted $=92.5 \%$ ). There was no surgical contraindication after systemic assessment.

Reverse-direction VATS left upper lobectomy via interlobar fissure was used for this patient. Lying on the right side with chest padded high, the patient, underwent double-lumen endotracheal intubation under general anesthesia. The observation port was located in the 7 th intercostal space of the left chest midaxillary line, about $1.5 \mathrm{~cm}$ in length, where a $30^{\circ} 10-\mathrm{mm}$ high-definition videoassisted thoracoscope was placed, and the operating port was located in the fourth intercostal space between the left chest midclavicular line and the anterior axillary line, about $4 \mathrm{~cm}$ in length. The operator stood on the ventral side of the patient, and a mirror holder stood by the patient's back.

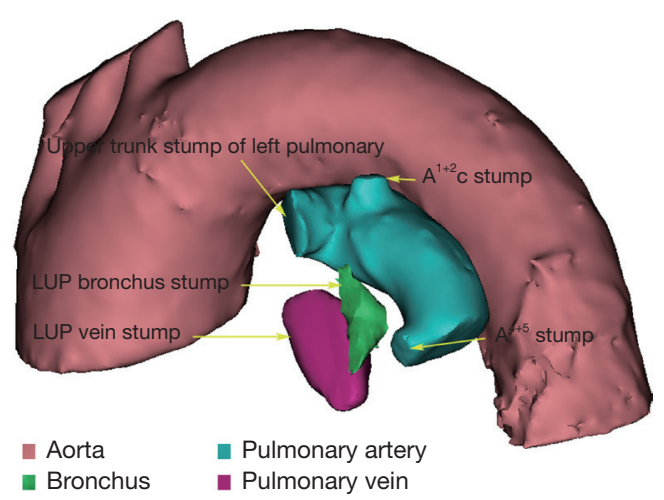

Figure 1 Schematic diagram of main operation steps. 1. Transect the $\mathrm{A}^{4+5}$ and $\mathrm{A}^{1+2} \mathrm{c}$ branches $\rightarrow 2$. Transect the LUP bronchus $\rightarrow 3$. Transect the upper trunk of the left pulmonary artery $\rightarrow 4$. Transect the LUP vein. LUP, left upper pulmonary.

An ultrasonic knife was used as mainly energy-based device.

Operation steps (Video 1): (I) the anterior fissure was dissociated and interlobar lymph nodes were dissected with an energy device, and the LUP anterior mediastinal pleura was cut open from bottom to top until the upper trunk of the left pulmonary artery was exposed; (II) the posterior fissure was dissociated, and the LUP posterior mediastinal pleura was cut open from bottom to top; (III) the $\mathrm{A}^{4+5}$ and $\mathrm{A}^{1+2} \mathrm{c}$ branches were exposed and transected with a stapler; (IV) the LUP bronchus was exposed, and peribronchial lymph nodes (station 12) were separated to the distal end, and the LUP bronchus was transected with a stapler; (V) the upper trunk of the left pulmonary artery was exposed and transected with a stapler; (VI) the LUP vein was transected with a stapler. The main Operation steps were shown in diagram (Figure 1). The LUP nodule was sent to freezing, and the pathological results suggested invasive adenocarcinoma. After dissection of the hilar (station 10L) and mediastinal (stations 4L, 5, 6, and 7) lymph nodes, a conventional chest tube was placed through the observation port for closed drainage, and the chest incision was sutured layer by layer after the lung was expanded.

All procedures performed in studies involving human participants were in accordance with the ethical standards of the institutional and/or national research committee(s) and with the Helsinki Declaration (as revised in 2013). Written informed consent was obtained from the patient for publication of this case report and accompanying images. A copy of the written consent is available for review by the editorial office of this journal.

After the operation, the patient's condition remained 
stable, without shortness of breath, fever, hoarse voice, lung air leakage, or pleural effusion. On day 5, chest CT examination was performed and the tube was removed, and the patient was discharged on day 6. Postoperative diagnosis: (LUL) invasive adenocarcinoma (pT1cN0M0, stage IA3, AJCC $8^{\text {th }}$ ).

\section{Discussion}

In single utility port and single-port VATS left upper lobectomy, surgery is limited by the operating space and operating angle. It is difficult to dissect and transect the LUP vein and the upper trunk of the left pulmonary artery, and there is a risk of vascular rupture and bleeding. These can be partially resolved through methods such as lowering intercostal incision, fully dissociating the blood vessels to the distal end and changing the lung traction angle (4-6). However, it is still a challenge for inexperienced thoracic surgeons, especially when they encounter severe adhesion of hilar vascular or calcification of hilar lymph node. To overcome this dilemma, we first transect the $\mathrm{A}^{4+5}$ and $\mathrm{A}^{1+2} \mathrm{c}$ branches. For one thing, these vessels are relatively thin and easy to expose. Even if the blood vessels rupture and bleed, this can be controlled more readily under thoracoscopy than if it occurs in the upper trunk of the left pulmonary artery, because it is directly on the field of view and is close to the operating port. The paths of these blood vessels make them easy to cut with a stapler or ligation, and there is no need to excessively free blood vessels or stretch the lobes. In addition, after transecting the $\mathrm{A}^{1+2} \mathrm{c}$ branch, if there is a single $\mathrm{A}^{1+2} \mathrm{~b}$ branch, it will also be dissected. The next step is the treatment of the LUP bronchus, which is considered key to this operation. Since the posterior mediastinal pleura has been cut open and the $\mathrm{A}^{4+5}$ and $\mathrm{A}^{1+2} \mathrm{c}$ branches have been transected, it is easy and safe to expose and transect the LUP bronchus. Sometimes peribronchial lymph nodes adhere tightly to the LUP bronchus, making them difficult to dissociate. At this time, the tongue bronchus and the proper segment bronchus can be dissected separately and then transected together. At this time, only the upper trunk of the left pulmonary artery and the LUP vein remain. These can be transected separately after simple dissociation. Because of the convenient angle of the stapler, we transected the upper trunk of the left pulmonary artery from behind the LUP vein, and we finally transected the LUP vein. If there were severely calcified and adherent lymph nodes between the upper trunk of the left pulmonary artery and the LUP vein, and they were difficult to separate, they could be removed at the same time because these lymph nodes are usually not metastatic lymph nodes.

In our method, the anterior and posterior mediastinal pleurae of the LUL were cut open first, whereupon dissection was performed from the bottom to the top through the interlobar fissure, avoiding any need to go back and turning the lung lobes repeatedly. Throughout the process, the LUL was pulled and pressed by bean curd block shaped small dry gauzes clamped by oval forceps. We believe that this method is especially suitable for patients with well-developed interlobar fissures and severe calcification and adhesion of hilar lymph node. If the interlobar fissure is partially developed, it can be slightly separated to expose the interlobar pulmonary artery, and then the tunnel method can be used to open it.

\section{Conclusions}

The proposed method helps expose the upper trunk of the left pulmonary artery and the LUP vein, simplifies the operation, and improves overall safety.

\section{Patient perspective}

The patient was very satisfied for this surgical method. She recovered smoothly and no postoperative complications were occurred.

\section{Acknowledgments}

Funding: None.

\section{Footnote}

Reporting Checklist: The authors have completed the CARE reporting checklist. Available at https://shc.amegroups.com/ article/view/10.21037/shc-21-15/rc

Peer Review File: Available at https://shc.amegroups.com/ article/view/10.21037/shc-21-15/prf

Conflicts of Interest: All authors have completed the ICMJE uniform disclosure (available at https://shc.amegroups.com/ article/view/10.21037/shc-21-15/coif). The authors have no conflicts of interest to declare.

Etbical Statement: The authors are accountable for all aspects of the work in ensuring that questions related 
to the accuracy or integrity of any part of the work are appropriately investigated and resolved. All procedures performed in studies involving human participants were in accordance with the ethical standards of the institutional and/or national research committee(s) and with the Helsinki Declaration (as revised in 2013). Written informed consent was obtained from the patient for publication of this case report and any accompanying images. A copy of the written consent is available for review by the editorial office of this journal.

Open Access Statement: This is an Open Access article distributed in accordance with the Creative Commons Attribution-NonCommercial-NoDerivs 4.0 International License (CC BY-NC-ND 4.0), which permits the noncommercial replication and distribution of the article with the strict proviso that no changes or edits are made and the original work is properly cited (including links to both the formal publication through the relevant DOI and the license). See: https://creativecommons.org/licenses/by-nc-nd/4.0/.

\section{References}

1. Liu C, Pu Q, Ma L, et al. Combinating the concepts of

doi: $10.21037 /$ shc-21-15

Cite this article as: Zhang S, Liu X, Liu J, Liu S, Wu W, Wang H. Reverse-direction video-assisted thoracoscopic surgery left upper lobectomy via interlobar fissure: a case report. Shanghai Chest 2022;6:8. single-port and single-direction in video-assisted thoracic surgery (VATS) lung cancer resection-Uniportal singledirection VATS lung cancer resection. Chinese Journal of Thoracic and Cardiovascular Surgery 2017;24:907-10.

2. Zhao T, Zhang $\mathrm{M}, \mathrm{Wu} \mathrm{W}$, et al. The implementation of single-direction approach in uniportal thoracoscopic lobectomy. Chinese Journal of Laparoscopic Surgery (Electronic Edition) 2018;11:295-9.

3. Lin Z, Wang L, Xi J, et al. Posterior approach for uniportal video-assisted thoracic surgery right upper lobectomy in the semiprone position. Chinese Journal of Thoracic and Cardiovascular Surgery 2019;26:53-6.

4. Wang Q, Cai YX, Deng Y, et al. Modular 3-cm uniportal video-assisted thoracoscopic left upper lobectomy with systemic lymphadenectomy. J Thorac Dis 2016;8:2264-8.

5. Chen Y, Lin JT, Dong S, et al. Uniportal video-assisted thoracoscopic surgery left upper lobectomy and systematic lymph node dissection with fused fissure. J Thorac Dis 2017;9:1375-81.

6. Ma C, Sun Y, Tian W, et al. Single Utility Port Complete Video-assisted Thoracoscopic Surgery of Left Upper Lobectomy: Report of 246 Cases. Chinese Journal of Minimally Invasive Surgery 2017;17:680-2, 7. 